\title{
Freedom of Press and Broadcasting Media in England and Bangladesh
}

\section{Tariq Adnan*}

MED 7009 Globalisation and Communication Law, Regulation and Ethics, Birmingham City University, UK

\begin{abstract}
Freedom of Press and Broadcasting Media is not alike. All indexes regarding press freedom distinctly show the differences between these two countries. Due to economic growth and social perspective, they are not same. But if we keep the keyword "Democracy" in line, both countries are moving in the same direction. Both are practicing democratic government. Journalistic approach is a way to measure a countries' democratic state.
\end{abstract}

Keywords: Press; Freedom; Bangladesh; South ASIA; England; Europe

\section{Introduction}

Journalism is an interactive, creative and a very large scaled profession who deals with people, soil, law, ethics, adventures and what not. A profession where seeking answers with the skill of asking questions, hunger for information and quick adaptation in a world where news runs faster than time. Journalism is the most accountable and a so sure way to face, observe and questioning the democracy.

Professionalism with a clear ethical stand drives a fair democracy. Journalists do collect, interpret and test a news what makes a bridge to the source, government and audience [1].

Journalists are liable only to them. Unbiased hunger for truth, in-depth information about an event and trustworthy ethical stand, assures the audience relying on them. So this is not unpredictable that government or groups with dishonest intentions feel insecure to journalists. Journalists can be a saviour in one sense as they raise awareness to the vast number of people with their words or photographs or documents. Besides, it could not be negligible that dishonest journalists can be a threat in a same way to the same group. Taking bribe and lowering to power could be a stumble to ruin the impression of the watchdogs of the society. The countries where freedom of speech violates on a daily basis is very critical for journalists to do their work. There news publishing against the government can draw an end to a journalist's professionalism. A bare-knuckle from the ruling party may cease the legislative rights in these cases. However, a fearless and truthful press can impede all wrongdoing of a government.

England, world's most famous country for their strong democracy, upholds their freedom of the press for over 300 years. Though in recent days, they may face some barriers as their government imposes some new laws. Though they stand $38^{\text {th }}$ position in world press freedom index which is way more advanced than Bangladesh who holds $144^{\text {th }}$ [2]. Bangladesh is a country where the relationship between government and press is very complex. After 2007 election, ruling party gradually absorbs press freedom as well as people's freedom of speech. In 2014, they introduced a new broadcasting act where government, political parties and administrative units are being put out of any journalistic criticism. Already most of the media owned by the opposition parties are being shut down.

This study briefly describes the current situation of England's press freedom, both print and broadcast media in the aspect of the incidents from last few years. For a comparison, Bangladeshi print and broadcast media rules in respected fields are also taken on the account. The study undergoes on similar fields from both the countries- freedom of the press.

\section{Context of Press Freedom}

Freedom does not mean to run boundlessly. At the early stage of human civilisation, only the leaders of a clan did have right to speak. After years and ages, human civilisation improvises. Philosophers react. Rebels revolts. Democracy takes place. The idea of country evolves. Today, each human soul is important as they have right to contribute a country's moral and productive building up directly. And people elect who governs them. And with that origination, journalists to make the whole process free and fair. They act like the eye of a society. Their thought-provoking opinions chain a government; rephrase the pathway, the goal, the ideology of the society.

A free press is a primary requirement. If we take the political side on the account, freedom of expression is the key and lifeline of a democratic system. In third world countries, where the education system is not that up to the mark, it is tough to motivate and engage the public in bigger aspect. Press has the power to reach out to the furthest corner of a land. Free, fair, educated press can be the most experienced teacher of a nation. On the other side, if the press continues to fight against their own freedom of expression, there is a great possibility that press might undergo a self-restriction and thus chained thyself to survive. Which opens a wide door for a government to bring fascism to their people. If we take a look at the press freedom index 2016 (Figure 1 ), we can see four levels of press freedom's presence worldwide.

The Ofcom regulates broadcasting media in England under its broadcasting code. These rules reflect the Communication Act 2003. BBC also regulates Ofcom from $3^{\text {rd }}$ April 2017. This is because to set a parameter for the audience, thus they depend on programs and news they watch and hear blindfolded. Ofcom ensures high quality of standard and thought-provoking programs for the British audience. They provide strict regulatory under charter and agreement of the programs to broadcast within ethical boundary and accuracy and the black mark indicates us that there is no freedom of the press at all. The

*Corresponding author: Tariq Adnan, MED 7009 Globalisation and Communication Law, Regulation and Ethics, Birmingham City University, UK, Tel: +44 (0)121331 5000; E-mail: itariq.adnan@gmail.com

Received November 15, 2017; Accepted Janaury 19, 2018; Published January 22, 2018

Citation: Adnan T (2018) Freedom of Press and Broadcasting Media in England and Bangladesh. J Mass Communicat Journalism 8: 359. doi: 10.4172/21657912.1000359

Copyright: ( 2018 Adnan T. This is an open-access article distributed under the terms of the Creative Commons Attribution License, which permits unrestricted use, distribution, and reproduction in any medium, provided the original author and source are credited. 


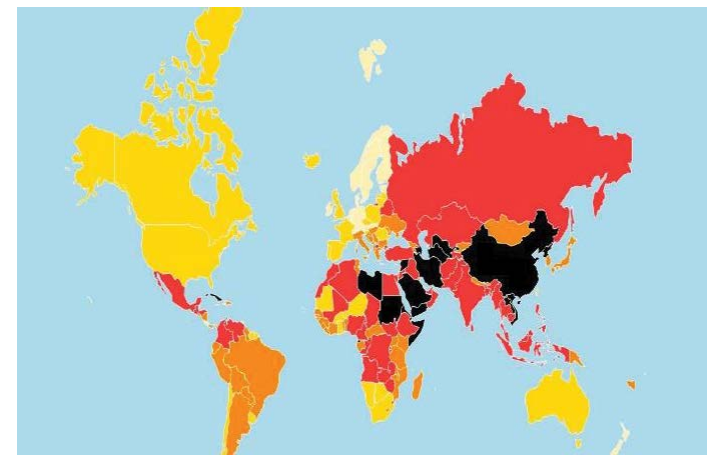

Figure 1: Press freedom index 2016 (Press freedom index ranking, 2017)

red coloured area is not also satisfactory. Yellow coloured countries have press freedom.

This study discusses two countries, England and Bangladesh-who stand distinctly separate level and point in the world freedom of the press index. It is actually difficult to measure the situation of a country's freedom of expression and press freedom level if an unfriendly ruling runs there. We only mark the place as black or red, but cannot go in depth and see how deep the problem beneath Impartiality [3].

The Ofcom provides three steps of codes. Firstly, broadcasting code, of which has ten sections including crime, religion, fairness, privacy, commercial references and so on. Secondly, cross promotion code where the legislative background of the coeds, principals, rules and guidance are given as an adjunct. Third is On-demand program service rules where administrative and editorial rules are briefly discussed.

\section{English Media and Her Regulations}

England stands on $38^{\text {th }}$ ( 4 places behind than previous year) position in 2016 at the Press freedom index provides by Reporters without Borders.

In England, both press and the government respects the rights within the legal framework in practice. However, there are few laws that compress press freedom, are on the table. Without any proven link to any specific terrorist act, the 2006 Terrorism Act criminalises speech that is considered to encourage terrorism. In August 2015, police seized a journalist's laptop as an earlier terrorist act from 2000 who had been contacting with Islamic State in Syria [4].

In November 2015, law enforcement team has got investigatory power over telecommunication companies after passed a bill by the government.

At the same year, International Press Standard Organisation launched an arbitration scheme, under what, they release affiliated publisher's annual statement, which includes the information of editorial standards and complaints handling records. IPSO has given a clear rule for the editors to practice. This 16 clauses code is written and administrated by the Editors' Code The committee which is enforced by IPSO. Like Ofcom's broadcasting codes, IPSO also emphasises on accuracy, privacy, discrimination and more [5].

Private media organisations have independence from any kind of political pressure or harassments. The BBC, whose governance and funding is under scrutiny since 2015 is also independent on the editorial side.

The National Union of Journalists is conducting a set of codes for the UK and Irish journalists since 1936. They are obligating 12 key principals for their members where truthfulness, privacy concern and avoid discrimination is being prioritised [6].

In 2011, now defunct News of the World, hacked thousands of people's phone. Which includes normal people to celebrity, ministers to the family of the murderers. Then Prime Minister David Cameron set up a public investigation which is led by Judge Lord Leveson. This investigation was mostly funded by former formula one boss Max Moley where culture, behaviour and ethics of the press have undergone an examination [7].

After hearing from high-profile witnesses, this investigation recommended to continue the self-regulation of the press but with new press standards govern by a new body according to new regulations backed by the legislation. This inquiry focused on the press, not the broadcasters who already regulate by Ofcom [8].

Following that, in 2013, the then main political party leaders, David Cameron, Nick Clegg and Ed Miliband, agreed to set up a new press watchdog by Royal Charter.

Theresa May's government triggered Section 40 of the Crime and Courts Act 2013. Under this enforcement, if an allegation is brought against a newspaper, they have to pay all legal costs even if they win. By this law, rich and powerful people can have a door to threat newspapers from pulling stories as the analysts opinioned [9].

Analysts claim that The MP 'scandal, Rotherham sex grooming, the murder of Stephen Lawrence - like investigations would never be possible if this section triggered then.

\section{Media and Press in England: Recent Bangladeshi Media and Her Regulations Incidents}

Bangladesh is standing in $144^{\text {th }}$ place in the Press Freedom index given by "Reporters without Borders". Bangladeshi journalistgovernment relation has not been an easy going since their independence in 1971. Media maintains an intimate relationship with the main political parties-Bangladesh Nationalist Party and the Awami League. As a result, Bangladesh journalists' union is not a single organisation. They are acting in separate groups- Bangladesh Federal Journalists union who are imitating the current opposition party and Dhaka Journalists Union who are obliged to the ruling party.

Media ban, journalists' harassment and media shut down are very common happenings in Bangladesh. In last one decade, four channels have shut down by the government only because of broadcasting news of government's crackdown.

Bangladesh government has given a new broadcasting policy in August 2014. With 7 chapters and clauses within it, the new policy has faced protest and criticism from media personnel and senior citizens of Bangladesh. The main opposition party has denominated this policy as "regressive and intended to gag media" $[10,11]$.

Regarding the policy, liberation war and holding its spirit emphasised most. Any statement or scene of the national defence and law enforcement agencies cannot be shown or broadcast by this new code of conduct. Government's officials are above of any kind of news or criticism. Religious, cultural and any political defamation has fallen under strict prohibition [12].

In third chapter article 3.2.1 says, no way a channel can broadcast any anti-state elements or programs. Yet, there is no such explanation of which program can be treated as such. 
Citation: Adnan T (2018) Freedom of Press and Broadcasting Media in England and Bangladesh. J Mass Communicat Journalism 8: 359. doi: 10.4172/2165-7912.1000359

Page 3 of 4

Article 3.2.2 imposes a restriction on baffling or false statement broadcasting, but there is no guideline under which media can identify or judge a statement. So most of the cases, the government uses this clause to back opposition's words.

Article 3.2.3 describes that government's approved program as the speech of President or the prime minister, emergency declaration of the weather forecast or health, official press notes must be broadcast with high priority. It is not feasible to give pressure on private media channels to broadcast president or prime minister's speech or official press notes. The government owns three channels for that.

Article 3.6.7 is accused of making confusion on broadcasting programs from local side and foreign. It restricts local media not to broadcast programs that are not keeping and maintaining local cultural spirits but at the same time, there are no restrictions on the foreign programs. There is no clear definition of mature content or privacy limits. Maintaining native cultural values seems lack edge without a proper guideline.

Article 4.1.1 has ceased the independence of the language, style and message of advertisement and programs.

Article 5.1.5 barred on broadcasting any program that mocks law enforcement agencies. 5.1.7 Prohibits broadcasting news or program that goes against any friend countries.

An independent and fair broadcasting commission needs to be formed, says article 6.1.1, but there are no specific guideline or outline or time limit for that.

\section{Media and Press in Bangladesh: Recent Threats on Press}

Since liberation, Bangladesh faces a tension between political parties. As of every sector is being politicised, media, judiciary, university are not out of that. Each government comes with abusive laws against opposition and tries to make their ruling era illegally extended. Two main political parties-Bangladesh Nationalist Party and Bangladesh Awami League place themselves on the opposite pole of ideology and acts.

News channel ban, journalists hassle and arrest, print and broadcast media shut down, women journalists' harassment, death threat, bribery, the too much politically biased opinion given by the journalists are regular in Bangladesh. Beside of that, lots of online portals have formed in recent years who don't even own proper name or license or policy or even qualified journalists. They are setting up to fulfil political agendas, incendiary writings, violent photographs and videos against their political opposition. This culture becomes frightfully outbound when supporters from the political parties spread this news and on the other hand, general people are becoming allergic to journalists and political parties. Healthy democracy thus dying day by day.

On 29 August 2002, Ekushey TV, which was formed at the time of Awami league government was banned for more than four years by then-ruling party BNP for broadcasting biased news. Ekushey TV was then-leading and popular TV channel in Bangladesh which was formed by former BBC journalist Simon Dring. His work permit was cancelled and forced to sell his share in ETV after BNP government takes place, in early 2000.

On 17 April 2006, An elderly photojournalist Zahirul Haque was beaten by Police at the Chittagong stadium where Australia versus Bangladesh cricket match was on the grass (Figure 2).

Police accused Zahirul of entering the stadium without permission.
Nadia Sharmeen, a former reporter at Ekattor TV, was attacked by Hefazot e Islam supporter while covering a rally and protest. Hefazot had set forth earlier that no women could cover their news.

From 2010 to 2016, it was the worst time for media to survive. Mahmudur Rahman, editor of "Amar Desh" newspaper was being arrested from his office and kept in jail for more than thousand days for continuous publishing of anti-government reports. Amar Desh is still closed (Figure 3).

In 2013, the government shut down Diganta TV who was charged with reporting on governments' crackdown. Islamic TV, Channel One is also being shut down for different charges who were owned by the opposition party.

Shawkat Mahmud, president of the Bangladesh Federal Union of Journalists was accused and arrested for arson strike on a bus during a protest running by the oppositions.

British-Bangladeshi journalist and former editor of Jayjaydin, Shafiq Rehman was arrested on a charge of an alleged plot to kidnap prime minister's son (Figure 4).

On March 2017, Basundhara group owned newspaper "Kalerkantha" fallen under criticism of the people of Bangladesh to draw a falsified report against North South University students. They claimed NSU student protest against Basundhara group as Islamic Extremist's attack.

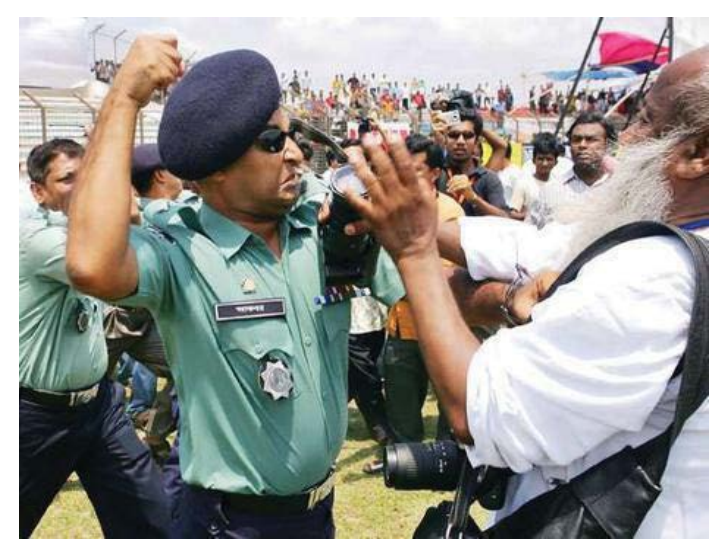

Figure 2: Zahirul Haque beaten by Police.

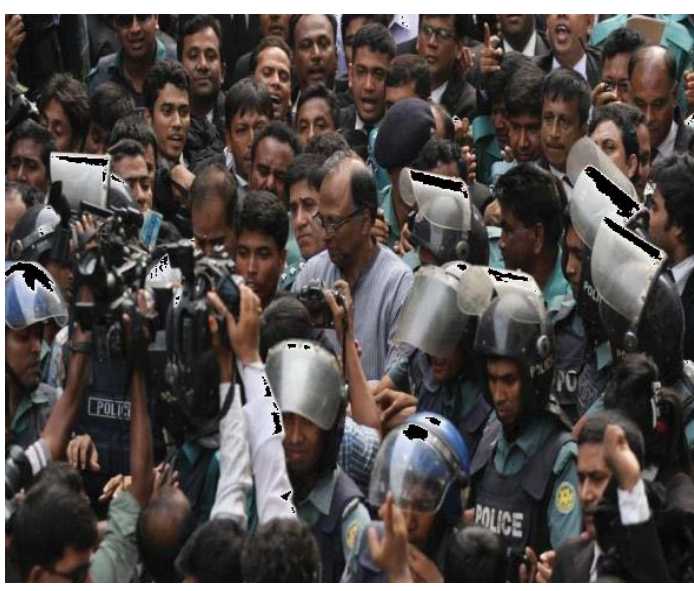

Figure 3: Mahmudur Rahman arrested and taken to Jail. 


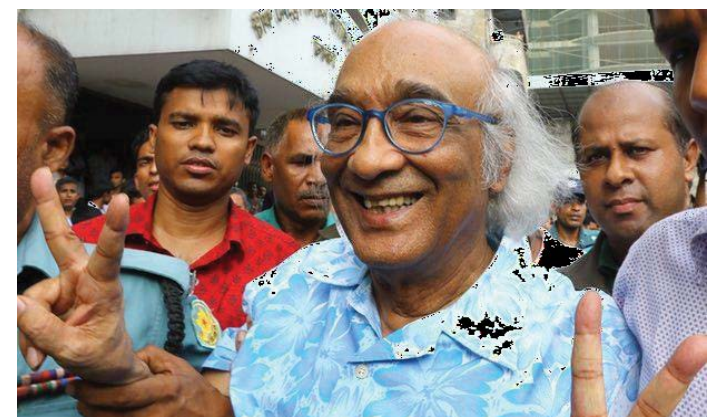

Figure 4: Shafiq Rehman arrested for plotting against Prime Minister Family.

\section{Conclusion}

England is a country where true democracy practices intensely. Government and journalists know their boundary of ethical and investigative proceedings. Political leaders try to drag the bridle of the voice of the journalists in some cases, but there is always room for legal actions and legislation. But in a developing country, where corruption and hunger for power strikes with intend to target, applying freedom of speech seems impossible then. Two groups of the journalists have made the situation complex there. There is no authentic and reliable spokesperson in press industry. When one group raising voice against something, opposition denies forcefully. Privacy and discrimination are another awfully broken oath in Bangladesh. Whoever holds money and power, is safe. Normal people do not have any representative in the press sector in that sense. Praising political parties and power, it goes in vain to contribute to the society even journalists have realization. Without freedom of the press, this unhealthy practice of arbitrarily use of words or even silence would bring withering impact on democracy and country on later days.

\section{References}

1. Herbert $J(2000)$ Journalism in the Digital Age: Theory and Practice for Broadcast, Print and Online Media. New York: Focal Press.

2. 2. (2017) Press freedom index. Reporters without borders.

3. Ofcom (2017) Introduction to Ofcom's Operating Framework for the BBC. London: Ofcom.

4. (2016) Freedom House.

5. (2016) International Press Standard Organisation.

6. (2011) NUJ code of conduct. National Union of Journalists.

7. (2016) Press regulation: What you need to know. BBC UK.

8. (2016) The Spectator.

9. (2017) Daily Mail Online.

10. Galhotra S (2014) Restrictive broadcast policy in Bangladesh raises concerns. Committee to Protect Journalists.

11. Bergman D (2014) New Bangladesh media policy faces opposition.

12. Mushtaq Ahmed (2014) Broadcast policy to give govt final control. 